\title{
A exposição escolar: una nova imagem para o século XXI
}

Patrícia Isabel Veiga Mousinho ${ }^{1}$

\begin{abstract}
Alguns falam numa "revolução na sala de aula»: a chegada da "realidade virtual» e da sala de aula sem paredes (Giddens, 2001, pág.515)
\end{abstract}

\begin{abstract}
Resumo
Neste artigo, abordamos as diferentes fases do Projeto Inovação Expográfica em Contexto Educativo desde a concepção à sua operacionalização. O projecto, coordenado pelo Professor Mário Moutinho, foi desenvolvido na Universidade Lusófona de Humanidades e Tecnologias (ULHT) e resultou duma parceria estabelecida entre o Centro de Estudos Interdisciplinares em Educação e Desenvolvimento (CeiED) e o Laboratório Experimental de Museologia e Educação (LEME). O projecto teve como finalidade desenvolver metodologias expográficas em contexto escolar e disseminar recursos expográficos nomeadamente no âmbito das novas tecnologias de informação e inovação.
\end{abstract}

Palavras-chave: inovação expográfica, novas tecnologias, contexto escolar

1 Mestranda em Educação, Instituto de Educação, Faculdade de Ciências Sociais, Educação e Administração (FCSEA) da ULHT patriciaivmousinho@hotmail.com 


\begin{abstract}
In this article, we discuss the different phases of the research project Expographic Innovation in Educational Context, from the conception to its operation. The project, was developed at the Lusophone University of Humanities and Technologies (ULHT) and resulted from a partnership between the Interdisciplinary Center for Studies in Education and Development (CeiED) and the Experimental Laboratory of Museology and Education (LEME) . The project aimed to develop expographic methodologies in secondary schools and disseminate resources, particularly in the context of new information technologies and innovation.
\end{abstract}

Keywords: expographic innovation, new technologies, school contexto

\title{
1- Introdução
}

O trabalho docente exige uma constante actualização, um conhecimento aprofundado da realidade e das motivações pedagógicas dos alunos bem como uma adaptação das práticas pedagógicas à modernidade e às novas correntes de pensamento didáctico.

As novas tecnologias são uma realidade à qual poucos podemos fugir atualmente, na realidade, "a expansão da tecnologia de informação parece influenciar a educação de várias formas, assumindo algumas delas talvez uma importância fulcral" (Giddens, 2001, pág.513).

Os tablet - através do conhecido projeto ManEEL, da responsabilidade da DGEstE-Alentejo - já entraram na sala de aula, os manuais interativos são um recurso amplamente utilizado pelos docentes e a internet substituiu, quer acreditemos ou não na veracidade de dados que encontramos, 
as enciclopédias na hora de elaborar um trabalho de pesquisa. Por isso, creio que estamos em condições de responder afirmativamente às questões colocadas por Giddens (2001) "irão o computador, o cd-rom e o vídeo substituir crescentemente o livro escolar? E continuarão as escolas a existir, de alguma maneira, sob a forma em que existem hoje, se as crianças, em vez de se sentarem em filas a escutar o professor, ligarem os seus computadores para aprenderem?" (pág.515).

Esta é a geração da imagem, do "aqui e agora", do estímulo visual constante e da interatividade. Esta é a geração que cresceu com a presença da internet, esse produto que reflete a postura e a mentalidade do mundo atual, como refere Giddens (2001) "é o produto [a internet] de um mundo que deixou de estar dividido um mundo posterior à queda do muro de Berlim" (pág.473).

No entanto, e apesar de toda esta evolução dentro da sala de aula e na forma como, na generalidade, se leciona em Portugal, quando visitamos as escolas, continuamos a encontrar a típica exposição nas paredes do edifício escolar, com as cartolinas e um texto extenso e maçudo, no qual pretendemos colocar de forma exaustiva todos os conhecimentos acerca do assunto abordado. Existe, efetivamente, um desfasamento entre a realidade virtual dos nossos alunos - que vivem entre smartphones e computadores - e a forma como alguns docentes continuam a encarar a essência de uma exposição escolar, ou como refere Giddens (2001) "os jovens de hoje já estão a crescer numa sociedade de informação e estão muito mais familiarizados com estas tecnologias do que muitos adultos - incluindo os seus professores" (pág.515)

Com vista a resolver esta discrepância, e no âmbito do Laboratório Experimental de Museologia e Educação da 
Universidade Lusófona de Humanidades e Tecnologias (ULHT) surge o projeto "Inovação Expográfica em Contexto Educativo".

\section{O Projeto Inovação Expográfica em Contexto Educativo}

Este projecto resultou duma parceria estabelecida entre o Centro de Estudos Interdisciplinares em Educação e Desenvolvimento (CeiED) e o Laboratório Experimental de Museologia e Educação (LEME). O CeiED surge no contexto da Universidade Lusófona de Humanidades e Tecnologias de Lisboa como uma unidade de investigação para as áreas da Educação, Património, Desenvolvimento Humano e Museologia. Apresenta como três objetivos principais a realização de um trabalho de investigação de qualidade e relevância social nas áreas da Educação e do Desenvolvimento Humano, a promoção de um serviço à comunidade através do trabalho de investigação que desenvolve e da possibilidade de melhoria no que concerne à formação inicial, contínua, especializada e pós-graduada a todos os atores da área educativa e, por último, permitir também um reforço da formação avançada.

Apresenta uma estrutura tripla, assente em três grupos de investigação: Educação, Identidades e Políticas Públicas; Aprendizagem, Comportamento e Formação e Cultura, Memória e Território, esta última integra o LEME. No caso específico do nosso projeto, inserimo-nos na área 1 de intervenção do LEME: Museologia.

No que concerne à área 1 - Museologia - refere Moutinho (2014): “o LEME pretende ser um lugar de reflexão e de investigação experimental, que ajuda escolas e museus da escola a redefinir as suas práticas, fornecendo-lhes conhecimentos e 
ferramentas necessárias para criar exposições dinâmicas" (cf http://www.ceied.ulusofona.pt/pt/investigacao/labs-pt/lemept).

Através deste projeto o LEME pretende introduzir nas escolas uma nova conceção de recurso expográfico, demonstrando a sua mais-valia no contexto educativo, nomeadamente, na transmissão de conhecimento.

É prática corrente nos vários estabelecimentos de ensino, independentemente do nível de ensino, a elaboração de exposições. Normalmente, a mesma surge associada a uma data histórica, a uma celebração nacional ou quando específica de uma disciplina, associada a um determinado conteúdo programático. Assume, portanto, um carácter didático e pretende ser uma forma lúdica de abordar alguns temas, de demonstrar outra vertente do conhecimento transmitido em contexto escolar. Contudo, e apesar do esforço empreendido ao longo dos anos, temos que reconhecer que a típica exposição escolar foi perdendo a sua aptidão atrativa de cativar as novas gerações que não a reconhecem como uma fonte de conhecimento mas apenas como um elemento "decorativo" presente nas paredes do edifício escolar. A exposição escolar perde deste modo o seu principal objetivo: transmitir conhecimento.

O projeto Inovação Expográfica em Contexto Escolar pretende mudar a imagem da exposição escolar, bem como, trazê-la de volta para o século XXI. Os objetivos deste projeto, através da realização duma exposição com um tema comum às várias escolas envolvidas, são: "desenvolver metodologias expográficas para projetos a realizar em contextos escolares; avaliar, adaptar e disseminar recursos expográficos em particular no campo das 
novas tecnologias de informação e inovação e identificar necessidades e promover o desenvolvimento de novos produtos e processos".

Pretende-se, com esta nova abordagem Expográfica, que a exposição escolar se torne num elemento interativo, que desperte curiosidade no aluno, que lhe permita aprender algo de novo, recorrendo aos recursos tecnológicos de que dispomos no nosso quotidiano. Não podemos, também, negar a panóplia de informação que nos é possível introduzir numa exposição se utilizarmos estes recursos tecnológicos - vídeos, fotografias, entrevistas, entre outros - que permitem de forma quase contraditória reduzir os elementos físicos da mesma aumentando exponencialmente o seu conteúdo (o lema less is more abordado de outra perspetiva).

O projeto, que terminou agora o primeiro de três anos, tem como objetivo prático a elaboração de uma exposição interativa, recorrendo à realidade aumentada, em contexto escolar.

Relativamente à sua área de atuação, o LEME pretende desenvolver o seu projeto em todo o território nacional através duma rede cooperativa estabelecida com inúmeros estabelecimentos de ensino e que permita, desta forma, uma disseminação das novas práticas expográficas por todo o país, rentabilizando os recursos que cada instituição detém.

Numa primeira fase do projeto, foram convidadas a participar algumas escolas de várias zonas do país, sendo a maioria da zona centro. Contudo, e como podemos comprovar pelo número de escolas que conseguiu efetivamente apresentar a sua exposição, nem sempre a introdução de novos conceitos e novas formas de percecionar a atividade educativa decorrem de forma natural e rápida. As quatro escolas que apresentaram exposições foram 
Agrupamento de Escolas Frei Gonçalo de Azevedo (São Domingos de Rana - Cascais), E.B. 2/3 Aquilino Ribeiro (Oeiras), Escola Profissional de Cuba (Cuba) e Escola Secundária c/3으 ciclo do Ensino Básico de Amora (Amora).

De forma a tornar o projeto mais unificado, estabeleceu-se um tema comum - Património Cultural Material e Imaterial - o qual deveria ser abordado de forma individual por cada escola. Com o intuito de aproximar o projeto dos alunos que o iriam concretizar, o tema deveria ser escolhido pelos mesmos, nomeadamente, que elemento do Património seria abordado na exposição. Contudo, e tendo em consideração que estávamos a trabalhar conteúdos escolares, na escolha do tema os docentes tiveram em consideração a integração do mesmo com o normal decorrer das atividades letivas.

Foram selecionadas as turmas, em cada escola, que iriam trabalhar no projeto, bem como, o tema a abordar - sempre dependente do tema-base Património Cultural Material E Imaterial. Numa primeira fase os docentes envolvidos no projeto recolheram os vários elementos - fotografias, vídeos, entre outros - para posteriormente, e numa formação ministrada pela professora Ana Moutinho, aprendermos a trabalhar os vários elementos com o recurso a três programas: Vuforia - prepara marcadores e converte cada imagem 2D num conjunto de pontos referenciados, os quais vão ser lidos pela ARCamera do Unity -, Miro - permite converter vídeos para poderem ser visualizados em iPhone ou Android - e Unity - onde construímos a app de cada exposição associando os vídeos previamente tratados aos marcadores.

Num processo construtivo, as várias fotografias foram convertidas em marcadores, os quais foram associados aos 
vídeos. No final da formação, todos os presentes puderam testar a aplicação e visualizar os seus vídeos em realidade aumentada. Posteriormente, a app foi colocada na PlayStore para poder ser descarregada para qualquer equipamento (com sistema operativo Android), permitindo a visualização da exposição. Seguindo a perspetiva do projeto, smartphones, tablets, computadores e demais equipamentos tecnológicos não podem ser vistos como um inimigo que deve ser eliminado totalmente das nossas escolas - até porque essa seria uma batalha inglória , mas sim, como um equipamento que nos pode ajudar na transmissão de conhecimento.

\section{Considerações finais}

Todos os elementos envolvidos no projeto referiram um nível de adesão bastante positivo obtido por parte dos alunos, permitindo uma desmistificação do conceito de realidade aumentada, bem como, um conhecimento e posterior domínio bastante satisfatório dos programas utilizados para a elaboração da exposição. Os alunos responsáveis pelo projeto participaram ativamente na recolha e edição dos materiais - entrevistas, vídeos, fotografias - e divulgaram para toda a comunidade educativa a sua exposição, não tendo esta sido feita exclusivamente no dia da inauguração.

Os docentes apontaram como pontos negativos 0 desconhecimento que a maioria da população ainda apresenta face a estes recursos tecnológicos - leitura de QRCode, download de apps - e o tempo fora do contexto escolar que o projeto exige. Frequentemente para procederem à recolha de materiais, os docentes tiveram que articular com os colegas de 
outras áreas disciplinares. O envelhecimento do pessoal docente cria também algumas dificuldades na introdução das novas tecnologias em contexto expográfico. A elaboração do projeto obrigou, também, ao desenvolvimento de competências e questões anexas, nomeadamente, a criação de QRCode, que serviram de elementos complementares aos marcadores.

Após o balanço do primeiro ano de projeto, e tendo como ponto de partida o sucesso conseguido neste primeiro ano, pretende-se expandir o projeto a mais turmas, envolver outras escolas e garantir a autonomia completa das escolas na elaboração das app.

Com vista a uma implementação mais rigorosa do mesmo, será oficializado um protocolo com as várias escolas participantes para que possam ser submetidos a aprovação e, consequentemente, possam ser atribuídas horas não letivas aos docentes para a realização do projeto. A ULHT apostará, também, na formação dos docentes, mais concretamente, em três áreas: elaboração de elementos expográficos em 3D, utilização do software e Aurasma e elaboração de QRCode. Continuarão a estar disponíveis os técnicos associados ao LEME para resolução de questões de cariz técnico que possam surgir durante a elaboração da exposição. De referir que nesta segunda fase é objetivo da estrutura organizativa que as escolas se tornem completamente autónomas na recolha de materiais, elaboração da exposição e criação da respetiva app. A inovação neste segundo ano de projeto passará pela abertura do mesmo a um maior número de turmas (e consequentemente de alunos) nas várias escolas e a possibilidade de introduzir um elemento em 3D - possivelmente o logotipo da escola e/ou da exposição no projeto. 
Para o próximo ano de projeto, o grupo de trabalho decidiu que os agrupamentos e as escolas participantes do projeto terão liberdade para escolher o tema da exposição, de acordo com as motivações do grupo.

As várias escolas envolvidas no projeto apresentam a documentação necessária para a implementação do mesmo em contexto escolar.

A Educação responde às necessidades da população, não é neutra nem independente da sociedade onde se pratica. Julgo que se torna vital desenvolvermos novas competências, socorrernos de novas ferramentas que permitam melhorar o ensino, modificar comportamentos pedagógicos que já não se coadunam com o século XXI.

Resta-nos perceber que o futuro da educação surge-nos sempre como uma incógnita que temos que ir lentamente desbravando porque como refere Giddens (2001) "num mundo de espantosas mudanças tecnológicas, ninguém pode ter a certeza daquilo que o futuro reserva" (pág.475).

\section{Referências}

Giddens, A. (2001). As consequências da Modernidade. Oeiras: Celta.

Moutinho, M. (2014). Leme disponível em http://www.ceied.ulusofona.pt/pt/investigacao/labs-pt/leme-pt, consultado em 16 de Março de 2016. 